\title{
Smart Sanitation-Biosensors as a Public Health Tool in Sanitation Infrastructure
}

\author{
Emma Rary 1,2, Sarah M. Anderson 1,2 ${ }^{\mathbb{D}}$, Brandon D. Philbrick 2,3, Tanvi Suresh ${ }^{2}$ \\ and Jasmine Burton $2, *$ (1) \\ 1 Rollins School of Public Health, Emory University, Atlanta, GA 30322, USA; emmarary@gmail.com (E.R.); \\ sarah.margaret.anderson@gmail.com (S.M.A.) \\ 2 Wish for WASH Thinks, Inc, Atlanta, GA 30338, USA; brandon.philbrick@emory.edu (B.D.P.); \\ tanvi.suresh96@gmail.com (T.S.) \\ 3 Emory University School of Medicine, Atlanta, GA 30322, USA \\ * Correspondence: jasminekburton@wishforwash.com
}

Received: 1 June 2020; Accepted: 27 June 2020; Published: 16 July 2020

check for updates

\begin{abstract}
The health of individuals and communities is more interconnected than ever, and emergent technologies have the potential to improve public health monitoring at both the community and individual level. A systematic literature review of peer-reviewed and gray literature from 2000-present was conducted on the use of biosensors in sanitation infrastructure (such as toilets, sewage pipes and septic tanks) to assess individual and population health. 21 relevant papers were identified using PubMed, Embase, Global Health, CDC Stacks and NexisUni databases and a reflexive thematic analysis was conducted. Biosensors are being developed for a range of uses including monitoring illicit drug usage in communities, screening for viruses and diagnosing conditions such as diabetes. Most studies were nonrandomized, small-scale pilot or lab studies. Of the sanitation-related biosensors found in the literature, 11 gathered population-level data, seven provided real-time continuous data and 14 were noted to be more cost-effective than traditional surveillance methods. The most commonly discussed strength of these technologies was their ability to conduct rapid, on-site analysis. The findings demonstrate the potential of this emerging technology and the concept of Smart Sanitation to enhance health monitoring at the individual level (for diagnostics) as well as at the community level (for disease surveillance).
\end{abstract}

Keywords: sanitation; toilet; sewage; wastewater-based epidemiology; global health; health sensor; biosensor; biological sensor

\section{Introduction}

Global health is the area of research and practice that prioritizes improving health and achieving health equity for people worldwide [1]. It emphasizes transnational health issues and embodies the idea that any one country cannot isolate itself from the public health challenges facing other nations [1]. With increased globalization, infectious diseases of today's world spread and affect larger populations more rapidly than they ever have before. Global threats require global solutions that are unified; therefore, nearly 70 national governments have partnered with international organizations and nongovernmental stakeholders to 'prevent, detect and respond' to disease threats [2]. This initiative, the Global Health Security Agenda (GHSA), acknowledges that outbreaks do not respect borders and that a pathogen can travel across continents in a matter of hours [2]. GHSA is multisectoral and multilateral; in addition to governments, GHSA membership includes the Global Health Security Agenda Consortium, a collective of nongovernmental organizations, including RTI International (formerly Research Triangle Institute) and Water Aid, as well as academic institutions [2]. Since its 
inception in 2014, the GHSA has informed the response to epidemics like Novel Coronavirus (COVID-19), Zika virus, Avian Influenza and the Ebola Virus [2]. In 2019, the United States released its own Global Health Security Strategy to affirm its commitment to the GHSA and outlined its plans for responding to infectious disease threats including Public Health Emergencies of International Concern (PHEICs), as declared by the World Health Organization (WHO) [3].

In addition to being international, GHSA initiatives are multi-sectoral, involving improvements across clinical, agricultural and technological spheres. Similarly, the WHO calls for innovative ways to connect communities, non-governmental organizations and private sector companies to improve health. WHO outlines priorities for strengthening health systems around the globe by expanding effective health services and ensuring equitable access to medical products and technologies [4]. The water, sanitation and hygiene (WASH) sector is a key area to target such improvements as it has the potential to prevent at least $9.1 \%$ of the global disease burden and $6.3 \%$ of all deaths [5]. Adequate WASH infrastructure is essential for providing quality healthcare, improving infection control, reducing the spread of resistant pathogens, promoting social and economic development and maintaining personal dignity. Thus, the United Nations (UN) 6th Sustainable Development Goal (SDG) aims to "achieve access to adequate and equitable sanitation and hygiene for all and end open defecation, paying special attention to the needs of women and girls and those in vulnerable situations" by 2030 [6]. Adequate sanitation must be safely managed throughout the sanitation chain and improved sanitation services are those that separate excreta from human contact, including improved pit latrines, pour-flush toilets, flushing toilets, sewage systems and septic systems [7].

These services are regularly monitored to ensure that infrastructure is properly functioning and monitoring health outcomes, such as infectious and chronic diseases, could be integrated into this process. Improved sanitation services can be leveraged for public health surveillance using emerging technologies that examine the characteristics of waste to collect real-time data on human health and behaviors [8]. The concept of Smart Sanitation could be a useful approach in making health monitoring more efficient, comprehensive and less resource intensive. The Toilet Board Coalition defines Smart Sanitation as a way to build resilience in cities, communities and sectors by utilizing Fourth Industrial Revolution technologies to improve the collection and monitoring of wastewater for both individualized and aggregate-level preventative health surveillance [8].

In the past decade, wastewater-based epidemiology has emerged as an innovative approach to survey and evaluate population-level exposure to chemical and biological compounds by analyzing biomarkers found in sewage $[9,10]$. Biomarkers are useful for characterizing exposures specific to human consumption as they can target metabolites and excretion products that are not associated with environmental sources [11]. Currently, biomarkers are being developed and validated to quantify community consumption of pharmaceuticals, illicit drugs and pesticides, as well as to detect specific diseases [11]. Compared with traditional survey methods, wastewater-based epidemiology is cost-effective, rapid and does not rely on self-reported data [11]. Still, biomarker data often require off-site preparation and analysis by trained laboratory personnel, which are limitations that could potentially be addressed with autonomous biosensor technologies.

Biosensors input biological responses that occur as a body's reaction to an external stressor, such as variation in $\mathrm{pH}$, temperature or enzymatic activity and convert them into a measurable, electrical signal [12]. Today, digital technologies increasingly interact with the biological world and biosensors have become a powerful tool in quantifying the health of human bodies and populations [13]. Related to sanitation, biosensors can enhance population health monitoring and prevent outbreaks through detecting specific biomolecules in urine and wastewater samples [11]. Biosensors can also be used to assess health interventions with little cost to research participants [14]. In addition to wastewater-based epidemiology, biosensors can assess the health of individuals by monitoring behaviors such as toilet usage and health indicators such as urine flow [15]. Biosensors are currently being developed for use in industrial wastewater treatment facilities and drinking water systems for quality control and early detection of system failures $[16,17]$. The WASH field is a prime area for the development and 
implementation of biosensor technologies in lieu of traditional methods for sample collection and analysis. This literature review addresses current research surrounding biosensors as a tool for public health surveillance and individual health monitoring which could be applied to reach global health security and health systems strengthening goals. This systematic review will assess how biosensors are being used in sanitation infrastructure to monitor human health.

\section{Materials and Methods}

This study follows the Preferred Reporting Items for Systematic Reviews and Meta-Analyses (PRISMA) statement [18].

\subsection{Inclusion and Exclusion Criteria}

Studies about the use of biosensors in WASH infrastructure were included if they were written in English and were written between the year 2000 and the time of our systematic review. Both gray literature and peer-reviewed literature were included. Papers were excluded if the use of biosensors was primarily implemented for environmental monitoring or other outcomes not directly related to human health. The full inclusion and exclusion criteria are listed in Table 1.

Table 1. Inclusion and Exclusion Criteria.

\begin{tabular}{|c|c|c|}
\hline Category & Included & Excluded \\
\hline Publication Language & English & \\
\hline Study types and designs & $\begin{array}{l}\text { Systematic reviews, random controlled } \\
\text { trials, product pilots/trials (non-random), } \\
\text { program reports, news articles describing } \\
\text { the use of biosensors by organizations }\end{array}$ & \\
\hline Publication Type & $\begin{array}{c}\text { Peer-reviewed articles and gray literature } \\
\text { (including program reports and reputable } \\
\text { news articles about product pilots) }\end{array}$ & $\begin{array}{c}\text { Textbooks, product manufacturer } \\
\text { documents such as schematics, patents }\end{array}$ \\
\hline Intervention type & $\begin{array}{l}\text { WASH interventions involving biosensors } \\
\text { aimed at improving human health either at } \\
\text { a public health (e.g., biosensors used in } \\
\text { wastewater treatment plants to evaluate } \\
\text { effectiveness of filtration systems) or } \\
\text { personal health (e.g., biosensors in toilets in } \\
\text { participant's homes to alert the presence of } \\
\text { a certain bacteria) level }\end{array}$ & $\begin{array}{l}\text { Interventions that do not utilize a biosensor, } \\
\text { do not relate to human waste and sanitation } \\
\text { (e.g., environmental/ecological monitoring } \\
\text { as the sole use of biosensors, sensors used } \\
\text { in industrial wastewater or sensors applied } \\
\text { to drinking water) or were not directly } \\
\text { related to a human health outcome }\end{array}$ \\
\hline Publication dates & 2000 to the present & Literature dated 1999 and prior \\
\hline
\end{tabular}

\subsection{Data Sources, Search Terms and Screening for Inclusion}

A systematic literature search was conducted from January to April 2020 to identify all relevant research and trials that met the inclusion criteria. The literature search was conducted in electronic databases (Embase, CDC Stacks, Nexis Uni, PubMed and Global Health) to gather peer-reviewed articles and gray literature. Searches used the following keywords-(i) terms related to WASH ("sanitation," "toilet," "sewage," "wastewater-based epidemiology"); (ii) "global health"; and (iii) terms related to biosensors ("health sensor," "biosensor," "biomarker," "biological sensor").

Each database was assigned to a reviewer. Abstracts and titles of retrieved literature were screened for relevance and those that were clearly ineligible were excluded (e.g., articles written in a language other than English or published before the year 2000). Retrieved articles and reports that were not excluded after the initial screening were reviewed using a checklist comprising all exclusion and exclusion criteria presented in Table 1. Articles that passed this second level of screening were included for data extraction and all excluded articles were recorded in an Excel spreadsheet. 


\subsection{Information Extraction and Quality Assessment}

After study selection, study characteristics including study design, country where the study was conducted, whether data collected was at the individual or community level, type of technology applied, study setting (toilet or latrine, community sewage system, treatment facility, etc.), purpose of sensor (to detect a virus, hormone, pharmaceutical substance, etc.) and specific strengths and weaknesses identified by paper authors were recorded in Excel. A second reviewer verified study selection and data extraction. Disagreements were resolved by a third reviewer. Reviewers coded the data and generated themes following the reflexive thematic analysis process [19]. Deductive and inductive codes were created and applied to the included papers. Codes such as "rapid," "ease of use," and "works remotely" were applied to the text only when directly mentioned by the study authors rather than as an interpretation of the data by the research team. Themes were derived from the explicit content of the data following a semantic approach [19]. No meta-analysis was conducted because of the low number of studies eligible for inclusion and the heterogeneity of study aims and measures.

To assess the strength of reporting in selected papers, reviewers evaluated adherence to the Strengthening the Reporting of Observational Studies in Epidemiology (STROBE) statement for observational studies [20]. If the STROBE guidelines were not applicable to the study design, reviewers assessed the limitations and potential sources of bias both reported by study authors and identified by the research team. Risk of bias was not used as exclusion criteria but was reported in the results and discussion sections.

\section{Results}

This systematic literature review retrieved a total of 961 articles. After duplicates were removed, 959 papers were screened for eligibility. After screening the abstract for relevance, 849 papers were excluded and an additional 89 articles were excluded after a full-text review, as they did not fit the inclusion criteria outlined in Table 1. A total of 21 articles (18 peer-reviewed and 3 articles published in gray literature) were included in analysis (Figure 1, Table A1).

\subsection{Study Characteristics}

Table 2, Table 3 and Appendix A Table A1 summarize the characteristics of the included papers. There was heterogeneity in the country of study, as there were 15 countries and one multi-country study represented among the 21 papers. The majority of these articles described biosensors in laboratory experiments and the remaining were pilot studies and editorials. Biosensors were used to gather individual- and community-level data. Most data were collected in toilets or wastewater systems, but others included testing patient samples of excreta in a clinical setting and even agriculture, where estrogen levels were measured in urine which could both assess human health and the suitability of urine as fertilizer [21]. Of the biosensors used in toilets, studies also included "smart toilets," self-contained and autonomous technologies that analyze the user's urine and feces for personalized health monitoring. 


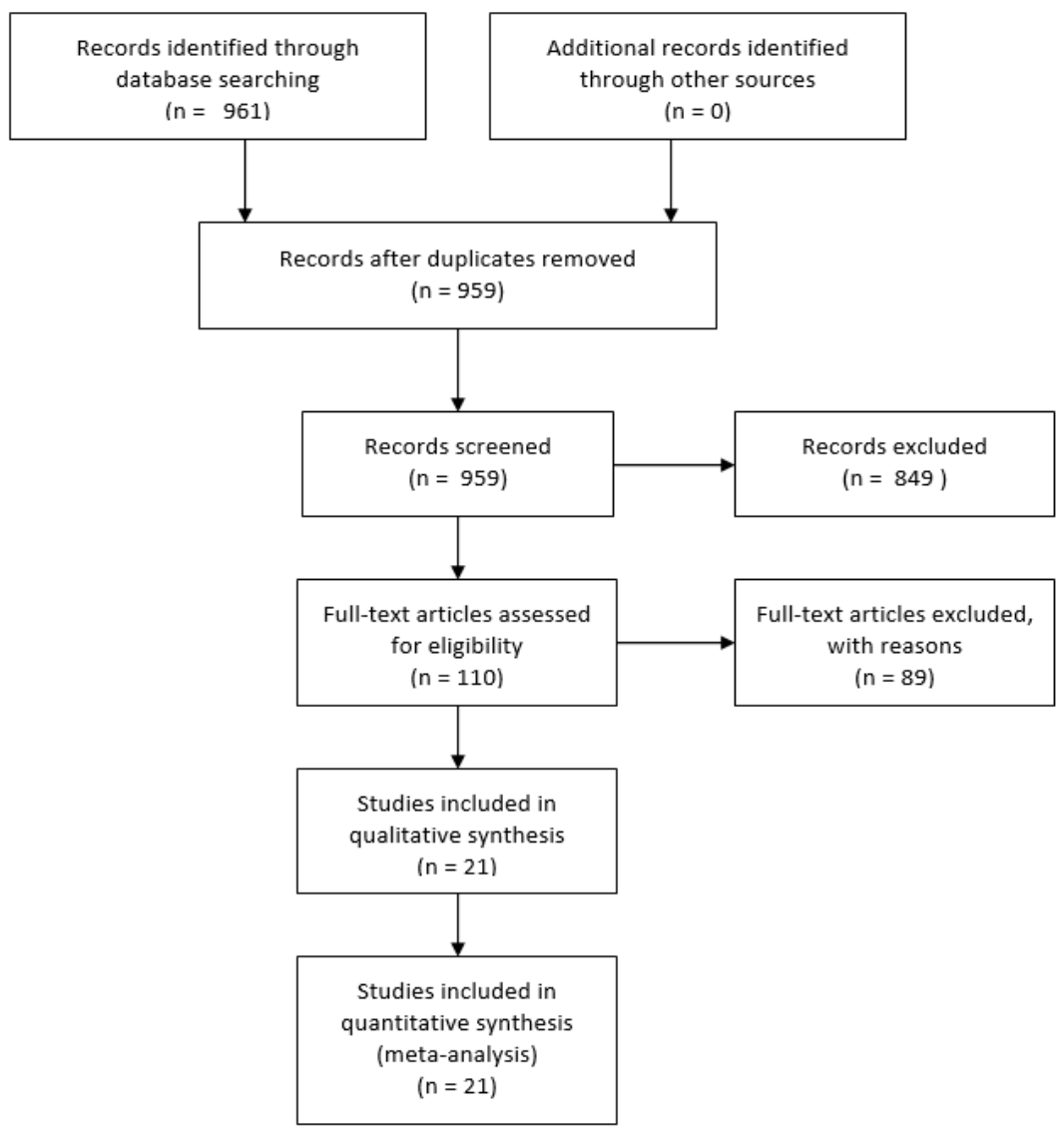

Figure 1. Study Selection.

Table 2. Study Characteristics.

\begin{tabular}{ccc}
\hline Codes & Frequency & Reference Number \\
\hline Intended Setting for Use of Biosensor & \\
Toilet & 8 & {$[22-29]$} \\
Wastewater & 8 & {$[11,30-37]$} \\
Bathroom & 1 & {$[38]$} \\
Agriculture & 3 & {$[39,40]$} \\
Purpose of Sensor/Health Outcome Measured & {$[21]$} \\
Patient Stool/Urine Sample in clinical setting & 4 & \\
(Biosensors that measured multiple health outcomes are repeated) & {$[23,26,39,40]$} \\
Measure temperature & 1 & {$[24]$} \\
Diagnosis of a health condition (e.g., diabetes) & 2 & {$[22,28]$} \\
Measure gut health (CO ${ }_{2}$ or microorganisms) & 4 & {$[27]$} \\
Measure blood sugar & 4 & {$[31,32,36]$} \\
Detect presence or quantify of medications or illicit drugs & 3 & {$[11,30,39,40]$} \\
Detect Biomarkers of Disease & 3 & {$[25,29,38]$} \\
Determine latrine/toilet usage & 1 & {$[34,35,37]$} \\
Detect chemicals/heavy metals & 1 & {$[21]$} \\
Detect Estrogen & & {$[33]$} \\
\hline Lstimate population size by detecting human population biomarkers & 1 & \\
\hline Study Type & 4 & {$[21,23,26-37,40]$} \\
Pilot study & 1 & {$[11]$} \\
\hline Editorial & $16,24,25,38]$ \\
\hline
\end{tabular}


Table 2. Cont.

\begin{tabular}{|c|c|c|}
\hline Codes & Frequency & Reference Number \\
\hline \multicolumn{3}{|l|}{ Population of Interest } \\
\hline Individual & 10 & {$[22-24,27-29,31,38-40]$} \\
\hline Community & 11 & {$[11,21,25,26,30,32-37]$} \\
\hline \multicolumn{3}{|l|}{ Samples Tested } \\
\hline Artificially prepared sample (e.g., chemical added to purified water) & 5 & {$[9,14,15,18,21]$} \\
\hline $\begin{array}{l}\text { Unmodified sample collected from the field or test subject } \\
\text { (e.g., wastewater or sewage samples) }\end{array}$ & 13 & {$[1-4,6,7,10,11,13,16,17,19,20]$} \\
\hline No samples taken (e.g., motion detection for latrine use) & 3 & {$[5,8,12]$} \\
\hline \multicolumn{3}{|l|}{$\begin{array}{ll}\text { Article Type } \\
\end{array}$} \\
\hline Peer-reviewed & 18 & {$[21,22,24-27,29-40]$} \\
\hline Gray Literature & 3 & {$[11,23,28]$} \\
\hline \multicolumn{3}{|l|}{ Author's Stated Next Steps } \\
\hline Improve sensor and/or resolve errors & 9 & {$[1,2,4,5,8,10,16,18,20]$} \\
\hline Clinical Trials & 2 & {$[9,13]$} \\
\hline Ready for use in toilets or wastewater systems & 6 & {$[7,11,14,15,17,21]$} \\
\hline Unspecified/no next steps stated by the author & 4 & {$[3,6,12,19]$} \\
\hline
\end{tabular}

Table 3. Themes of interest.

\begin{tabular}{|c|c|c|}
\hline Codes & Frequency & Reference Number \\
\hline \multicolumn{3}{|c|}{ Biosensor Characteristics } \\
\hline Portable & 11 & {$[11,22-25,30,33-35,38,40]$} \\
\hline Remote/Hands-off & 7 & {$[11,24-26,28,36,38]$} \\
\hline On-site analysis (no separate lab test needed) & 12 & {$[11,22-24,26-29,34-36,40]$} \\
\hline Continuously gathering data/longitudinal data collection & 7 & {$[11,24,25,27,28,31,38]$} \\
\hline $\begin{array}{l}\text { Easy to use without extensive technical knowledge, time or } \\
\text { money involved }\end{array}$ & 9 & {$[21,22,24,27,30,32,37,38,40]$} \\
\hline \multicolumn{3}{|c|}{ Comparison to Current Methods } \\
\hline More Rapid than conventional data collection methods & 8 & {$[11,23,26,32-35,39]$} \\
\hline Less Rapid than conventional data collection methods & None mentioned & n/a \\
\hline Higher user acceptability/less invasive & 7 & {$[22-27,38]$} \\
\hline $\begin{array}{l}\text { Less user acceptability due to obstruction of their daily } \\
\text { behaviors, feeling discomfort from being surveyed, etc. }\end{array}$ & 1 & [26] \\
\hline Low Cost & 14 & {$[11,21,23-25,30-35,37-39]$} \\
\hline High Cost & None mentioned & $\mathrm{n} / \mathrm{a}$ \\
\hline
\end{tabular}

Biosensors in these studies were developed for a variety of uses in sanitation infrastructure which ranged from gathering data about specific health outcomes, such as quantifying drug consumption or screening for infectious diseases, to monitoring individual health-related behaviors, such as tracking latrine/toilet usage. Many biosensor and technology types were represented, including DNA biosensors that could detect both cancer markers and pathogens [30], disposable carbon electrode sensors to detect pathogenic bacteria [39] and smart toilets that quantify $\mathrm{CO}_{2}$ as a proxy measure for microbiome health [22].

\subsection{Effectiveness of Biosensors as Described in Included Papers}

Among the 21 studies, five of the sensors were described as ready for use in toilets or wastewater systems while nine required further design improvements or trials. The large proportion of biosensor technologies in the prototype stage demonstrates that their use in sanitation is a relatively new and growing field. 
The majority of papers mentioned that the biosensors were cost-effective and produced results more quickly compared to the current standard method for detection. Many of the biosensors detected the target substance on site and in real time rather than traditional surveillance methods that often require intermittent manual sample collection and off-site laboratory analysis. As Yang and colleagues described in a paper about using biosensors to monitor community health in sewage systems:

"Compared to conventional analytical tools, biosensors can provide rapid response times, ultrasensitive detection of biomolecules and the potential to be miniaturized for portable assays requiring minimal sample processing." [11]

Biosensors have the ability to continuously collect data, often remotely/hands-off, reducing the resources needed to collect information and improving the ability to detect outcomes early or serve as early warning systems. The majority of sensors in this study were portable, allowing for samples to be taken in a variety of locations. Passive data collection using biosensors is often less invasive than other methods, such as blood tests or colonoscopies [23,24] and is more reliable than self-reported data regarding health behaviors [25]. When discussing the benefits of smart toilets specifically, Park and colleagues explained that:

"The intersection of continuous health monitoring and the valuable clinical information obtained from analyzing human excreta lies in the smart toilet. This toilet system is expected to have a major impact on health monitoring research, as the toilet enables longitudinal monitoring of human health with minimal interference of human behavior. It enables patients to reliably obtain data for their own health as well as enabling investigators to conduct large clinical trials." [26]

Many papers stated limitations of the use of biosensors, either from their performance in the current study or in future applications. Lab experiments conducted in ideal conditions, especially those that tested artificially prepared samples, would require further testing of biosensors for direct use in wastewater and sewage systems. While papers often cited that maintenance needs of biosensors were less intensive than current methods, smart toilets and other sensors often require regular cleaning [31,41]. One paper specifically states that, "Most of the bacterial biosensors that are currently available are large, require electronics or are too complicated to operate in [developing] countries" [25].

Specifically concerning sensors in toilets, the effects of environmental variables, including whether the user was standing or sitting and the presence of irregular airflow, could affect the biosensor results $[25,26,31,38]$. One paper explicitly mentioned that while user acceptability of biosensors in toilets "was within an acceptable range," participants expressed concerns about "privacy protection and data security" as well as the use of cameras identifying toilet users by "analprint recognition" [26]. Authors also raised concerns about the need to validate the lifetime of the biosensor in hot operating environments [24].

\subsection{Bias and Study Quality}

Most of these studies were small-scale, non-randomized pilot or lab studies. Only four [22,24,25,38] papers were eligible to be assessed for reporting quality with the STROBE guidelines for observational studies and all four met at least 17 of the 22 STROBE reporting criteria. While 19 out of the 21 papers were published in peer-reviewed literature, many of these biosensors are in a pre-experimental phase. The lack of randomization, representative samples and adequate controls present among papers in this literature review warrants caution when drawing any generalizable conclusions. Due to these limitations and the nascent nature of this field, further product implementation and research are needed to determine whether biosensors offer improved detection of outcomes of interest compared to the current standard of care. 


\section{Discussion}

\subsection{Strengths and Weaknesses of Biosensors in Sanitation Infrastructure}

This literature review shows that there is interest in continued prototyping and piloting of biosensors in sanitation infrastructure. These emerging technologies have the potential to gather preventative and behavioral health data about individuals and populations that could save time and money compared to traditional methods. From as early as 2014, mainstream publications and companies have promoted the concept of Smart Sanitation by predicting and provocating that sewage systems will become 'smart' and could include 'lab-on-chip biosensors' which will permit continuous data collection and real-time surveillance for viral outbreaks at the aggregate level [14]. As one of the papers in our literature review stated:

"Infectious diseases require rapid or even real-time detection to assess whether there is a need for the containment of the disease carriers to certain areas and prevent the development of an epidemic. To this end, there is a need to develop novel analytical tools that are able to accurately and rapidly monitor low levels of biomarkers/pathogens with minimal sample processing by unskilled personnel at the site of sample collection." [11]

Overall, our findings demonstrate that biosensors are being developed for use in the sanitation sector and preliminary results indicate that these biosensors can collect useful health-related data. Additionally, biosensors could be used to supplement standard tests that are already in place, such as colonoscopies, surveys or blood work testing to monitor individual and population health more holistically.

However, many papers noted that despite the promising advantages that biosensor technology can bring to health systems, this is a nascent field; therefore, it requires continued rigorous research and product development to reach its potential. Additionally, the lifespan of these various biosensors from both a hardware and surveillance perspective is largely unknown since the majority of the studies were lab-based or pilot studies [24]. These systems may be less accurate when applied to complex matrices such as sewage due to the variable mix of multiple contaminants, pathogens and physical trash (such as used diapers or menstrual health products) that perhaps were beyond the scope of many of the lab-based tests [11]. Some experiments that did test real wastewater, sewage or human specimen samples in the lab tried to account for temperature and other conditions that would be encountered in the field, but these technologies would still require pilot testing to ensure they would be reliable on site.

Additionally, there were some limitations that were only mentioned in a few papers (such as data privacy and impracticalities for low-resource settings $[25,26])$, while some limitations were not mentioned explicitly but are feasible (such as the potentially high costs related to biosensor technology or installation [26,27]). One paper also reported that "it is uncertain whether the algorithm [that was used with the biosensor to detect 'likely defecation events'] detects child feces disposal, child latrine training and menstrual [health] management events as 'likely defecation events'," which is also a notable limitation [25]. The majority of the actual limitations reported for biosensors embedded in sanitation infrastructure are technological rather than methodological barriers; therefore, they have the potential to be improved through iterative changes in the various devices' product designs and fine-tuning their technological prowess.

Despite the current limitations of biosensors, the long-term benefits outweigh the barriers. Public health stakeholders and WASH practitioners should not be deterred from adopting biosensors into sanitation products and infrastructure and should seek to further build the evidence base to determine the true global health potential that this Smart Sanitation technology could have.

\subsection{Population- and Individual-Level Health Considerations of Smart Sanitation}

Transforming sanitation infrastructure into a health diagnostic tool has implications both on the population and individual levels. At the population level, decision makers and public health 
practitioners could use biosensors that have been integrated into public sanitation infrastructure to mitigate and prevent infectious disease outbreaks [11]. On the individual level, there is also a demand for personal health monitoring. Similar to the biometric sensors integrated into consumer products such as the Apple Watch [42] or Fitbit [43], there appears to be a growing demand for individuals to use Smart Sanitation products to inform their lifestyle decisions and personal health investments. There are already at-home diagnostic methods available, such as Cologard's colon cancer screening kit where individuals can mail stool samples to be tested [44], which have potential to be improved and streamlined with the use of biosensors.

There has been an influx of Smart Sanitation private sector products on the market, such as TOTO's Flow Sky Toilet in 2018, a toilet that is equipped with a biosensor to capture the flow rate of the user's urine as an integrated urological medical examination [15], and Pampers' 'smart diaper' in 2019, which tracks an infant's sleep and urine patterns which is oftentimes a recommended practice from pediatricians [45]. These technologies represent the burgeoning market and demand from consumers for Smart Sanitation-related products for monitoring their individual health.

While there are a myriad of innovative opportunities for further research in the field, it is imperative that these products account for data privacy. Capturing data about individual-level health data, as opposed to information gathering about population-level health, must often adhere to regulatory standards such as the Health Insurance Portability and Accountability Act (HIPAA) Privacy Rule [46] in the United States of America and the General Data Protection Regulation (GDPR) [47] in the European Union. Smart Sanitation consumer products should be developed in such a way that is in line with these standards to safeguard individual-level health data while also fostering consumer trust as a result of transparent data protections in these products.

\subsection{The Covid-19 Era: Furthering the Case for Increased Smart Sanitation Research}

The need for embracing and further researching the implications of Smart Sanitation has been underscored by the widespread societal implications of the Novel Coronavirus (COVID-19). Recent studies have also shown SARs- CoV-2, the virus causing COVID-19, is shed in feces which means that fecal-oral contamination could be another route of transmission [48]. Biobot, a wastewater epidemiology startup, has conducted opioid and COVID-19 wastewater analytics and monitoring within the United States to create data-driven maps for community-level decision makers to see as the disease spreads in real time [49]. Researchers in Spain are now collecting samples approximately twice a week from over 250 wastewater treatment facilities for improved COVID-19 surveillance through sewage [50]. This would be an ideal place to implement biosensors in sewage systems, which would allow for this data collection to occur more quickly with less potential for exposure for field workers and lab technicians.

However, due to the nascent nature of this sector, the preventive health benefits of the Smart Sanitation Economy will likely not be realized quickly enough to meaningful impact the COVID-19 pandemic. Beyond current pathogenic testing, next generation Smart Sanitation biosensors could be made to detect a wide array of biomarkers to mitigate and monitor future epidemics.

\subsection{Limitations of this Review}

This review has a number of limitations. First, identifying findings that explicitly explained product/device failures or misuses in this sector was difficult. While this could be attributable to publication bias, it could also be because the field is so new that few reports of product trials exist at all or they are not publicly available. Second, the research team exclusively searched for gray literature in the Nexus Uni database, which may have missed internal product reports, news articles and other relevant information. Third, academic literature on this subject tended to focus on the mechanics of the technologies rather than the practicalities of the device in practice (such as cost, maintenance and usability), which is likely because these technologies are largely in the pre-implementation phase. 


\section{Conclusions}

The findings of this systematic review demonstrate the public health potential of biosensors as an emerging technology and how Smart Sanitation can be used to enhance health monitoring at the individual level as well as at the community level. Most studies were nonrandomized, small-scale pilot or lab studies and revealed that few biosensors have been used in toilet or human sewage settings outside of lab tests. Many of the biosensors provided real-time continuous data and were reported to be more cost-effective in terms both time and money when compared to traditional surveillance methods. The most commonly discussed strength of these technologies was their ability to conduct rapid, on-site analysis. The use of biosensors in sanitation is a nascent field that has the potential to promote global health security and strengthen health systems. In order to effectively develop and implement these technologies for public health surveillance and individual health monitoring at a large scale, more robust research is needed to evaluate and improve existing biosensors technologies to not only ensure the efficacy of their use but also their compliance with global data privacy and human study protocols. Additional research in this field could also identify gaps where next generation versions of the biosensor technologies can emerge.

Author Contributions: J.B. and E.R. conceptualized the review and E.R. acquired sponsorship to support the publication of this research; E.R., S.M.A., J.B., B.D.P. and T.S. participated in the data collection; S.M.A., E.R., J.B., B.D.P. and T.S. analyzed the data and E.R., J.B., S.M.A., B.D.P. and T.S. wrote the original draft; S.M.A., E.R., J.B., B.D.P. and T.S. reviewed and edited the document. All authors have read and agreed to the published version of the manuscript.

Funding: The authors received no financial support for the research and authorship. Emory University is providing support for the publication fees for open access publication of this article.

Acknowledgments: We are grateful to the Centers for Disease Control and Prevention's (CDC) post graduate fellowship support programs (such as the Oak Ridge Institute for Science and Education Fellowship and the Public Health Associate Program) that enabled us to navigate our way through conducting a rapid literature review. (J.B. and T.S. were post graduate fellows at the CDC through the course of this research). We are also grateful to the Emory University Library for supporting our review efforts (E.R., S.A. and B.P were postgraduate students at Emory University over the course of this research).

Conflicts of Interest: While J.B. has done contract work with the Toilet Board Coalition (cited in the paper) and all authors are affiliated with Wish for WASH Thinks, Inc, the authors declare no conflict of interest.

\section{Appendix A}

Table A1. Study Characteristics of Included Papers.

\begin{tabular}{ccc}
\hline Author, Publication Year, Country [ref] & Technology Used & Setting of Use in Study \\
\hline Yang et al., 2015, Europe (multiple) [11] & Multiple (review paper) & Wastewater \\
Jaatinen et al., 2016, Finland [21] & Whole cell sensor & Urine samples \\
Lucarelli et al., 2002, Italy [30] & Carbon electrode sensor & Wastewater \\
Webster et al., 2014, United States [39] & Carbon electrode sensor & Urine samples \\
Hirayama et al., 2010, Japan [22] & Infrared & Toilet \\
Soh, 2005, Singapore [23] & Electric biosensor & Toilet \\
Kawanami et al., 2012, Japan [24] & Thermocouple sensor & Toilet \\
Delea et al., 2017, Bangladesh [25] & Motion sensor & Toilet \\
Park et al., 2020, United States [26] & Smart toilet, DNA biosensor & Toilet \\
Masemola et al., 2020, South Africa [31] & Electric biosensor & Water \\
Chapron et al., 2019, Canada [38] & Infrared & Toilet \\
Ghosh et al., 2020, India [27] & Smart toilet, Transducer & Toilet \\
Porecha, 2015, United States [28] & Smart toilet & Toilet \\
Nakagawa et al., 2018, Japan [29] & Electrocardiogram & Toilet \\
Mao et al., 2019, China [32] & Colorimetric biosensor & Wastewater \\
Yang et al., 2015, United Kingdom [33] & DNA biosensor & Wastewater \\
Timur et al., 2004, Turkey [34] & Whole cell sensor & Wastewater \\
Gao et al., 2017, China [35] & Whole cell sensor & Wastewater \\
Pham et al., 2015, Germany [36] & Whole cell sensor & Wastewater \\
Gagnon \& Lajeunesse, 2008, Portugal [37] & Whole cell sensor & Wastewater \\
Bunyakul et al., 2015, Thailand [40] & Microfluidic immunosensor & Stool samples \\
\hline
\end{tabular}




\section{References}

1. Koplan, J.P.; Bond, T.C.; Merson, M.H.; Reddy, K.S.; Rodriguez, M.H.; Sewankambo, N.K.; Wasserheit, J.N. Consortium of Universities for Global Health Executive Board. Towards a common definition of global health. Lancet 2009, 373, 1993-1995. [CrossRef]

2. Division of Global Health Protection. About Global Health Security. Available online: https://www.cdc.gov/ globalhealth/healthprotection/ghs/about.html (accessed on 22 July 2019).

3. United States Government. United States Government Global Health Security Strategy; United States; White House Office: Washington, DC, USA, 2019; p. 32.

4. World Health Organization. Everybody's Business: Strengthening Health Systems to Improve Health Outcomes: WHO's Framework for Action; WHO Document Production Services: Geneva, Switzerland, 2007.

5. Cutler, D.; Miller, G. The role of public health improvements in health advances: The twentieth-century United States. Demography 2005, 42, 1-22. [CrossRef] [PubMed]

6. United Nations Economic and Social Council. Special Edition: Progress Towards the Sustainable Development Goals; Report of the Secretary-General; United Nations Publications: New York, NY, USA, 2019.

7. World Health Organization; United Nations Children's Fund. Sanitation. Available online: https://washdata. org/monitoring/sanitation (accessed on 22 July 2019).

8. Toilet Board Coalition. Smart Sanitation City: The Sanitation Economy at City Scale; Toilet Board Coalition: Geneva, Switzerland, 2018.

9. Devault, D.A.; Karolak, S. Wastewater-based epidemiology approach to assess population exposure to pesticides: A review of a pesticide pharmacokinetic dataset. Environ. Sci. Pollut. Res. Int. 2020, 27, 4695-4702. [CrossRef] [PubMed]

10. Sims, N.; Kasprzyk-Hordern, B. Future perspectives of wastewater-based epidemiology: Monitoring infectious disease spread and resistance to the community level. Environ. Int. 2020, 139, 105689. [CrossRef] [PubMed]

11. Yang, Z.; Kasprzyk-Hordern, B.; Frost, C.G.; Estrela, P.; Thomas, K.V. Community Sewage Sensors for Monitoring Public Health. Environ. Sci. Technol. 2015, 49, 5845-5846. [CrossRef] [PubMed]

12. Ali, J.; Najeeb, J.; Asim Ali, M.; Farhan Aslam, M.; Raza, A. Biosensors: Their Fundamentals, Designs, Types and Most Recent Impactful Applications: A Review. J. Biosens. Bioelectron. 2017, 8, 1-9. [CrossRef]

13. Schwab, K. The Fourth Industrial Revolution: What It Means and How to Respond. Available online: https://www.weforum.org/agenda/2016/01/the-fourth-industrial-revolution-what-it-means-andhow-to-respond/ (accessed on 22 July 2019).

14. Alm, E.; Turgeman, Y.J.; Ratti, C. Smart Toilets and Sewer Sensors Are Coming. Wired UK. 21 March 2014. Available online: https://www.wired.co.uk/article/yaniv-j-turgeman (accessed on 22 August 2019).

15. Shah, D. Toto Flow Sky Measures Urine Flow Just by Urinating in the Toilet. Available online: https://fareastgizmos. com/other_stuff/toto-flow-sky-measures-urine-flow-just-by-urinating-in-the-toilet.php (accessed on 21 August 2018).

16. Philp, J.C.; Balmand, S.; Hajto, E.; Bailey, M.J.; Wiles, S.; Whiteley, A.S.; Lilley, A.K.; Hajto, J.; Dunbar, S.A. Whole cell immobilised biosensors for toxicity assessment of a wastewater treatment plant treating phenolics-containing waste. Anal. Chim. Acta 2003, 487, 61-74. [CrossRef]

17. Joshi, N.; Wang, X.; Montgomery, L.; Elfick, A.; French, C.E. Novel approaches to biosensors for detection of arsenic in drinking water. Desalination 2009, 248, 517-523. [CrossRef]

18. Moher, D.; Liberati, A.; Tetzlaff, J.; Altman, D.G. Preferred reporting items for systematic reviews and meta-analyses: The PRISMA statement. BMJ 2009, 339, 332-336. [CrossRef]

19. Braun, V.; Clarke, V. Using thematic analysis in psychology. Qual. Res. Psychol. 2006, 3, 77-101. [CrossRef]

20. Von Elm, E.; Altman, D.G.; Egger, M.; Pocock, S.J.; Gøtzsche, P.C.; Vandenbroucke, J.P. STROBE Initiative the Strengthening the Reporting of Observational Studies in Epidemiology (STROBE) statement: Guidelines for reporting observational studies. J. Clin. Epidemiol. 2008, 61, 344-349. [CrossRef] [PubMed]

21. Jaatinen, S.; Kivistö, A.; Palmroth, M.R.T.; Karp, M. Effect of source-separated urine storage on estrogenic activity detected using bioluminescent yeast Saccharomyces cerevisiae. Environ. Technol. 2016, 37, 2172-2182. [CrossRef] [PubMed] 
22. Hirayama, K.; Hashimoto, H.; Takeshita, A.; Rui, C.; Noguchi, S.; Takezaki, Y.; Itoh, K. Correlation between Indicators of Intestinal Environment and Amount of Carbon Dioxide in Gas Excreted During Defecation. Biosci. Microflora 2010, 29, 135-141. [CrossRef]

23. Soh, N. Pee Power. Available online: https://advance-lexis-com.proxy.library.emory.edu/api/document? collection=news\&id=urn:contentItem:4GWK-FGJ0-0058-X2BC-00000-00\&context=1516831 (accessed on 14 May 2020).

24. Kawanami, S.; Horie, S.; Inoue, J.; Yamashita, M. Urine temperature as an index for the core temperature of industrial workers in hot or cold environments. Int. J. Biometeorol. 2012, 56, 1025-1031. [CrossRef]

25. Delea, M.G.; Nagel, C.L.; Thomas, E.A.; Halder, A.K.; Amin, N.; Shoab, A.K.; Freeman, M.C.; Unicomb, L.; Clasen, T.F. Comparison of respondent-reported and sensor-recorded latrine utilization measures in rural Bangladesh: A cross-sectional study. Trans. R. Soc. Trop. Med. Hyg. 2017, 111, 308-315. [CrossRef]

26. Park, S.; Won, D.D.; Lee, B.J.; Escobedo, D.; Esteva, A.; Aalipour, A.; Ge, T.J.; Kim, J.H.; Suh, S.; Choi, E.H.; et al. A mountable toilet system for personalized health monitoring via the analysis of excreta. Nat. Biomed. Eng. 2020, 4, 624-635. [CrossRef]

27. Ghosh, P.; Bhattacharjee, D.; Nasipuri, M. Intelligent Toilet System for Non-invasive Estimation of Blood-Sugar Level from Urine. IRBM 2020, 41, 94-105. [CrossRef]

28. Porecha, M. Soon, Poop down Memory Lane; No s\#@t Talk | MIT Team in City to Work on Smart Toilet That Will Capture Vital Data from Excreta. DNA. 29 January 2015. Available online: https://www.dnaindia.com/ mumbai/report-dna-exclusive-poop-down-the-memory-lane-2056431 (accessed on 22 August 2019).

29. Nakagawa, A.; Kim, J.; Nakajima, K. A Preliminary Study on Person Identification Using Toilet-Seat ECG. Trans. Jpn. Soc. Med Biol. Eng. 2018, 56, 183-189.

30. Lucarelli, F.; Kicela, A.; Palchetti, I.; Marrazza, G.; Mascini, M. Electrochemical DNA biosensor for analysis of wastewater samples. Bioelectrochemistry 2002, 58, 113-118. [CrossRef]

31. Masemola, D.P.; Mafa, P.J.; Nyoni, H.; Mamba, B.B.; Msagati, T.A.M. Gold nanoparticles modified exfoliated graphite electrode as electrochemical sensor in the determination of psychoactive drug. J. Environ. Sci. Health $B$ 2020, 55, 455-461. [CrossRef]

32. Mao, K.; Ma, J.; Li, X.; Yang, Z. Rapid duplexed detection of illicit drugs in wastewater using gold nanoparticle conjugated aptamer sensors. Sci. Total Environ. 2019, 688, 771-779. [CrossRef] [PubMed]

33. Yang, Z.; d'Auriac, M.A.; Goggins, S.; Kasprzyk-Hordern, B.; Thomas, K.V.; Frost, C.G.; Estrela, P. A Novel DNA Biosensor Using a Ferrocenyl Intercalator Applied to the Potential Detection of Human Population Biomarkers in Wastewater. Environ. Sci. Technol. 2015, 49, 5609-5617. [CrossRef] [PubMed]

34. Timur, S.; Seta, L.D.; Pazarlioğlu, N.; Pilloton, R.; Telefoncu, A. Screen printed graphite biosensors based on bacterial cells. Process Biochem. 2004, 39, 1325-1329. [CrossRef]

35. Gao, G.; Fang, D.; Yu, Y.; Wu, L.; Wang, Y.; Zhi, J. A double-mediator based whole cell electrochemical biosensor for acute biotoxicity assessment of wastewater. Talanta 2017, 167, 208-216. [CrossRef] [PubMed]

36. Pham, H.T.M.; Giersberg, M.; Gehrmann, L.; Hettwer, K.; Tuerk, J.; Uhlig, S.; Hanke, G.; Weisswange, P.; Simon, K.; Baronian, K.; et al. The determination of pharmaceuticals in wastewater using a recombinant Arxula adeninivorans whole cell biosensor. Sens. Actuators B Chem. 2015, 211, 439-448. [CrossRef]

37. Gagnon, C.; Lajeunesse, A. Persistence and fate of highly soluble pharmaceutical products in various types of municipal wastewater treatment plants. Wit Trans. Ecol. Environ. 2008, 109, 799-807. Available online: https://www.witpress.com/elibrary/wit-transactions-on-ecology-and-the-environment/109/19028 (accessed on 1 June 2020).

38. Chapron, K.; Lapointe, P.; Bouchard, K.; Gaboury, S. Highly Accurate Bathroom Activity Recognition using Infrared Proximity Sensors. IEEE J. Biomed. Health Inf. 2019. [CrossRef]

39. Webster, T.A.; Sismaet, H.J.; Conte, J.L.; Chan, I.J.; Goluch, E.D. Electrochemical detection of Pseudomonas aeruginosa in human fluid samples via pyocyanin. Biosens. Bioelectron. 2014, 60, 265-270. [CrossRef]

40. Bunyakul, N.; Promptmas, C.; Baeumner, A.J. Microfluidic biosensor for cholera toxin detection in fecal samples. Anal. Bioanal. Chem. 2015, 407, 727-736. [CrossRef]

41. Silva, N.; Gil, D.; Karmali, A.; Matos, M. Potentiometric Biosensor for Acrylamide Determination in Wastewater Using Wild Type Amidase from Pseudomonas Aeruginosa. Wit Trans. Ecol. Environ. 2008, 109, 789-798. Available online: https://www.witpress.com/elibrary/wit-transactions-on-ecology-and-theenvironment/109/19027 (accessed on 1 June 2020).

42. Apple, Inc. Watch. Available online: https://www.apple.com/watch/ (accessed on 1 June 2020). 
43. Fitbit, Inc. Products. Available online: https://www.fitbit.com/us/home (accessed on 1 June 2020).

44. Exact Sciences Corporation. Meet Cologuard. Available online: https://www.cologuardtest.com/meetcologuard (accessed on 1 June 2020).

45. Murphy Kelly, S. Pampers Is Making a "Smart" Diaper. Yes, Really. Available online: https://www.cnn.com/2019/07/19/tech/pampers-smart-diapers/index.html?utm_medium=social\&utm_ source=LINKEDIN_COMPANYbusiness\&utm_content=2019-07-19T21:37:49 (accessed on 22 August 2019).

46. U.S. Department of Health and Human Services. Standards for Privacy of Individually Identifiable Health Information ("Privacy Rule"); 45 CFR Part 160 and Subparts A and E of Part 164; United States Government Publishing Office: Washington, DC, USA, 2002.

47. EU General Data Protection Regulation (GDPR). Regulation (EU) 2016/679 of the European Parliament and of the Council of 27 April 2016 on the protection of Natural Persons with Regard to the Processing of Personal Data and on the Free Movement of Such Data, and Repealing Directive 95/46/EC (General Data Protection Regulation), OJ $2016 \mathrm{~L}$ 119/1; Publications Office of the European Union: Luxembourg; Available online: https://eur-lex.europa.eu/ eli/reg/2016/679/oj (accessed on 1 June 2020).

48. Chen, Y.; Chen, L.; Deng, Q.; Zhang, G.; Wu, K.; Ni, L.; Yang, Y.; Liu, B.; Wang, W.; Wei, C.; et al. The presence of SARS-CoV-2 RNA in the feces of COVID-19 patients. J. Med. Virol. 2020. [CrossRef] [PubMed]

49. Biobot Analytics, Inc. Biobot. Available online: https://www.biobot.io/ (accessed on 10 November 2019).

50. Baraniuk, C. Countries Begin Large-Scale Screening for SARS-CoV-2 in Sewage. The Scientist. 14 May 2020. Available online: https:/www.the-scientist.com/news-opinion/countries-begin-large-scale-screening-forsars-cov-2-in-sewage-67535 (accessed on 1 June 2020).

(C) 2020 by the authors. Licensee MDPI, Basel, Switzerland. This article is an open access article distributed under the terms and conditions of the Creative Commons Attribution (CC BY) license (http://creativecommons.org/licenses/by/4.0/). 